\title{
A ESQUERDA ONTEM E HOJE: o dilema entre igualdade e liberdade
}

\author{
Maria Francisca Pinheiro Coelho*
}

Resumo: Este artigo discorre sobre as idéias da Esquerda na década de 1960 e as mudanças de paradigmas a partir da década de 1990, após a queda do Muro de Berlim e o colapso do socialismo real. Aborda um conflito que perpassa a história do socialismo: a questão dos direitos civis. Analisa também os dilemas da esquerda ontem e hoje, com ênfase na relação entre política e liberdade. Sugere que concomitante com a defesa da justiça social, a identidade de uma esquerda contemporânea se define pela defesa da liberdade como valor fundamental e essência da política.

Palavras-chave: paradigmas da esquerda, socialismo, liberdade política, autoritarismo, democracia.

O que é ser uma Esquerda contemporânea? Em que medida seu passado pode lançar luz sobre o futuro? Essas questões persistem no debate sobre a Esquerda, sua identidade e sua atuação política no momento. Este texto desenvolve uma reflexão com base no dilema entre igualdade e liberdade, considerando como ontem as mobilizações da década de 1960, principalmente o legendário ano de 1968, e como hoje as mudanças no paradigma da esquerda a partir dos anos 80, fundamentalmente após a queda do Muro de Berlim, em 1989, e o colapso do socialismo real, em 1991.

No mundo moderno, os preceitos de igualdade e liberdade, guias da Revolução Americana e da Revolução Francesa, tornaram-

\footnotetext{
"Socióloga, professora da Universidade de Brasília. Atualmente, desenvolve pesquisa sobre o pensamento político da geração de 1968 no Congresso Nacional.

As idéias deste texto foram apresentadas na Conferência Nacional Caio Prado Júnior, promovida pela Fundação Astrogildo Pereira, na Câmara dos Deputados, de 17 a 19 de agosto de 2007.
}

Recebido em 6 ago. 2008 e aprovado em 9 set. 2008. 
se norteadores dos ideais de convivência humana. Todos nascem livres e iguais são as marcas da sociedade moderna que, do ponto de vista jurídico, aboliu as desigualdades fundadas nas diferenças de nascimento e status.

Entre os protagonistas da Revolução Francesa surgiu também o conceito de Esquerda, atribuído aos representantes do povo e das classes médias que se sentavam do lado esquerdo da Assembléia e que enfatizavam a luta pela igualdade, o combate à desigualdade econômica. O dilema entre igualdade e liberdade, como valores integrantes do ideal fundador e regulador da modernidade, vai estar presente na trajetória da Esquerda. As antinomias próprias do capitalismo, sistema promotor da igualdade de direitos, a cidadania, mas ao mesmo tempo reprodutor de desigualdades econômicas e sociais, constituirão alvo das críticas ao sistema, a partir das quais se constrói o campo da utopia socialista.

O referido dilema perpassa os ideais reformistas e socialistas desde o princípio, consistindo-se em termômetro de diferentes concepções políticas. A conhecida tensão é objeto de estudos clássicos no campo das Ciências Sociais. O dilema dá roteiro a uma das grandes polêmicas no pensamento político desde a origem.

Tocqueville $(1977,1979)$ institui os termos dessa oposição tendencial nas promessas da democracia. Indaga sobre a relação entre esses preceitos no contexto da tendência irrefreável da igualdade na sociedade moderna. Mais do que uma afirmação da excelência da liberdade, busca compreender em termos culturais a menor ou maior estima que os homens têm por ela, na medida em que existem sociedades democráticas que não cultivam o gosto pela liberdade. Reconhece os ganhos proporcionados com as condições de igualdade na democracia, mas sua preocupação central é com a liberdade, a virtude cívica, procurando mostrar aos homens como escapar do que denominou a tirania da maioria. 
Em meados do século XX, com o mundo dividido entre os blocos capitalista e socialista e a existência da "guerra fria", a reflexão sobre a liberdade é eixo condutor do pensamento político de Hannah Arendt (1989). A Esquerda, fortalecida com a expansão do socialismo no Pós-Guerra, não recebeu bem sua crítica igualando o totalitarismo de direita e de esquerda, estudado por ela com base na experiência coetânea do nazismo e stalinismo.

Em sua análise, ambos os regimes se sustentam na ideologia do terror, que tem como fundamento a lógica de uma idéia e a ausência de um princípio orientador da ação. Montesquieu utilizou a distinção entre princípios orientadores da ação para classificar as formas de governo. Segundo Arendt, o totalitarismo é uma nova forma de regime, diferente das ditaduras e tiranias do passado, por não ter um princípio orientador da ação e um inimigo visível. $\mathrm{O}$ inimigo no totalitarismo é invisível, pode ser qualquer um (Arendt, 1989). O objetivo desse regime é o domínio total e ele se fundamenta na destruição do espaço público e privado, o que leva o homem ao seu desenraizamento da sociedade. Para a autora (1987), sem liberdade não há espaço para a política, a condição humana da pluralidade e atividade política por excelência.

No final da década de 1980, com a queda do Muro de Berlim e, em seguida, o colapso do socialismo real o dilema entre igualdade e liberdade emerge com vigor. $\mathrm{O}$ fracasso do modelo socialista do Leste Europeu vai ter profunda repercussão no ideário da Esquerda. No plano das idéias, a reflexão sobre essa oposição tendencial vai ser retomada em estudos de Giddens para além da Esquerda e da Direita (1996) e sobre a terceira via (2001); de Bobbio sobre a validade do conceito de Esquerda (2006); de Jürgen Habermas (2002), Bauman (2003), entre outros, sobre os desafios da globalização, multiculturalismo, inclusão do outro, temas integrantes da agenda atual. 
Sob o impacto dos novos acontecimentos, a Esquerda procura redefinir caminhos da luta pela construção da justiça social e traços de um suposto modelo socialista. No entanto, no campo da Esquerda, multifacetado e plural, nem todas as tendências vão adotar uma postura crítica em relação ao passado ou ao modelo concreto utilizados, e ainda novos outros grupos e movimentos são criados cravados na velha tradição.

Este texto argúi sobre a necessidade de redimensionamento do enfoque acerca da liberdade no campo da Esquerda. Se, até a década de 1960, a questão da igualdade se constituiu a sua marca, enquanto a questão da liberdade é a marca do pensamento liberal, após a queda do Muro de Berlim e o colapso do socialismo real não é mais possível postular a oposição nesses termos. Novas estratégias e identidades devem ser inventadas.

A antinomia entre igualdade e liberdade precisa ser enfrentada como forma de sobrevivência e legitimidade da Esquerda contemporânea. Sem nenhuma pretensão de decretar o fim de uma ideologia, percebe-se que, na atualidade, a identidade da Esquerda requer, além da luta pela justiça social, a incorporação da liberdade e da democracia como valores universais.

\section{1}

Antes de demarcar os dois períodos, o da década de 1960 e o dos anos 80, e as principais bandeiras da Esquerda nesses momentos, buscar-se-á fazer uma digressão na história do século 20 , com o objetivo de identificar o conflito entre igualdade e liberdade que perpassa as divergências no interior da social-democracia na Europa e que levaram à sua principal dissidência, o bolchevismo, tendência predominante na Revolução Russa, de 1917.

O tratamento da questão da liberdade dividiu a esquerda na teoria e na prática até hoje, impedindo-a de construir uma 
única identidade. Poder-se-sia dizer que sempre existiram duas esquerdas: a democrática e a autoritária. Brandão (1997) refere-se à existência de duas almas do Partido Comunista: a alma democrática e a revolucionária, que defende o levante armado. As duas visões reivindicam o legado marxista (Coelho, 1993).

A origem desse conflito reside na abordagem distinta da questão da liberdade, debate anterior mesmo à tradição marxista. Essa reflexão já está presente no socialismo utópico e no anarquismo. A questão de como conciliar os princípios da igualdade e da liberdade será divisor de águas na polêmica entre anarquistas e comunistas. Contudo, no interior da tradição socialista, que englobará todas essas correntes, o marxismo se transformará na principal tendência.

Vale salientar que uma esquerda democrática não se identifica necessariamente com uma postura não revolucionária. Sua identidade reside em considerar a liberdade como valor fundamental e em agir com o objetivo de preservá-la.

O conceito de liberdade não comporta restrições aos direitos civis, porém há ênfases diferentes quanto à compreensão do conteúdo do conceito. O conceito liberal de cidadania enfatiza o lugar do indivíduo e seus interesses, sem se ater à coletividade. A visão liberal corresponde à liberdade dos modernos, uma liberdade negativa cuja finalidade seria livrar o indivíduo dos constrangimentos legais. A visão republicana ou de liberdade positiva enfatiza a preocupação com a res publica, com o bem coletivo (Belin, 1981).

A concepção republicana de liberdade, se bem que pressupõe a inclusão do conjunto dos direitos fundamentais, valoriza a inserção do indivíduo na vida pública. Não se restringe a uma interpretação individualista de liberdade, de ação voltada para si mesmo, mas tem a conotação de ação no mundo. A liberdade é assim percebida como um conceito nascido da política e a sua própria razão de ser (cf. Arendt, 1972). 
Na social-democracia alemã, um exemplo desse entendimento sobre a liberdade é a crítica de Rosa Luxemburgo, integrante da tendência libertário-revolucionária, aos rumos da Revolução Russa. Em escrito de 1918, classificou o regime implantado por Lenin de uma ditadura que não diferia de uma ditadura burguesa nem de um tipo de dominação jacobina. Prognosticou: o não respeito à questão democrática levaria necessariamente a uma barbarização da vida pública, com perseguições, atentados, fuzilamentos. Foi o que aconteceu.

A autora expressa a visão de que, quanto mais democrática a instituição, mais viva e forte é a pulsação da vida política das massas, mais direta e forte a ação que exercem. Em sua crítica, é enfática na defesa da liberdade:

Liberdade somente para os partidários do governo, para os membros de um partido, por numerosos que sejam, não é liberdade. Liberdade é sempre a liberdade daquele que pensa de modo diferente. Não por fanatismo da 'justiça', mas porque tudo quanto há de instrutivo, de salutar e purificante na liberdade política prende-se a isto e perde sua eficácia quando a 'liberdade' torna-se privilégio. (Luxemburgo, 1987, p. 166).

As revoluções socialistas que ocorreram depois da Revolução Russa foram seguidas de supressão das liberdades, implantação de regimes ditatoriais, decretação do partido único, perseguição e aniquilamento de dissidentes. Os que pensavam diferente da orientação política do regime eram perseguidos ou mortos pelo partido, que muitos tinham ajudado a construir. A maior parte das vezes, mortos não porque abdicaram de seus ideais revolucionários, mas porque tinham visões diferentes do processo políticorevolucionário. 


\section{2}

Na década de 1960, o espírito contestador e revolucionário ascendeu nos movimentos liderados fundamentalmente por gerações jovens. Em nenhuma outra década desse século, denominado por Eric Hobsbawm de "era dos extremos", a juventude mostrou tanta força como nessa época. E se houve um momento que correspondeu a um levante mundial simultâneo foi, sem dúvida, 1968.

O crescimento da educação em massa levou ao aumento da demanda no ensino superior, que passou por um período de expansão em todo mundo. Houve uma explosão no número de matrículas, mas existia uma insatisfação com a estrutura das universidades, que não estavam preparadas para as mudanças. Para o historiador, não surpreende, portanto, que a década de 1960 tenha se tornado a década da agitação estudantil por excelência (cf. Hobsbawn, 1995).

Essa década foi marcada pelo confronto de ideologias do PósGuerra. A divisão do mundo entre duas superpotências, Estados Unidos e União Soviética, e a existência da "guerra fria" gerava um clima de tensão permanente. A coexistência pacífica entre os dois blocos encobria um estado de guerra latente e políticas de cunho imperialista. Guerras e conflitos localizados faziam parte da disputa pelo controle do mundo.

Existia uma polarização entre os modelos de capitalismo e de socialismo. Rebeliões de juventude e contestações políticas de toda ordem caracterizaram essa década. A coragem e a determinação marcaram as lutas do período contra a guerra do Vietnam, o racismo, a opressão das mulheres, o imperialismo ianque e as ditaduras militares na América Latina.

Em todos esses movimentos os jovens foram os principais protagonistas. Movia-os uma paixão por um mundo melhor. Queriam construir uma nova sociedade, de preferência socialista. 
Sinceramente, não pareciam medir a relação de forças entre os movimentos e o poder dominante. Estavam dispostos a dar a vida por seus ideais. O ano de 1968 não admitiu neutralidade. O estilo de vida e o modo de pensar expressavam o comportamento dos jovens contra o conformismo e o status quo. ${ }^{1}$

Influenciados pelo espírito beligerante da época, chegavam mesmo a assumir como libertários modelos autoritários de sociedade. Naquele mundo dual e sem espaço para conciliações, aos gritos de liberdade, eles chegavam a perder a compreensão da liberdade como valor universal. Poucas vozes sensatas alertavam para os perigos iminentes da perda desse valor. Correspondia à separação entre os blocos socialista e capitalista uma nítida divisão entre os campos da Esquerda e da Direita. Os rebeldes não reconheciam que no interior de cada bloco coexistiam ideologias democráticas e autoritárias.

Os ventos da liberdade sopravam tanto no mundo capitalista quanto no socialista. As transformações nos costumes, nas artes, na música, rompiam com posturas retrógradas e inauguravam padrões novos e modernos de comportamento. O movimento feminista se firmava na luta pela igualdade de direitos entre os sexos. A escola de Frankfurt pregava um marxismo humanista, aproximando Marx e Freud. O pensamento de Marcuse inspirava as rebeliões estudantis ao mostrar os paradoxos da sociedade industrial, com sua cultura do consumo. A crítica da sociedade de massa, com seus subprodutos da alienação, uniformidade e conformismo, fortalecia o movimento da contracultura em todo mundo.

O Maio francês, com suas barricadas e a defesa da aliança operário-estudantil, estimulou levantes semelhantes no mundo capitalista. Se nesse sistema as contradições pareciam insuperáveis nos marcos da estrutura social, do lado socialista os problemas não seriam menores. Contudo, apesar das divergências políticoideológicas entre as orientações comunistas, maoístas, trotskistas e 
castristas, a esquerda na sua essência se mantinha fiel aos pilares do marxismo-leninismo: a revolução socialista e a ditadura do proletariado.

Em agosto de 1968, a crise política manifestou-se no bloco soviético com a invasão da Checoslováquia pelos tanques do Pacto de Varsóvia, reprimindo manifestações que visavam combinar socialismo com liberdades políticas. O movimento, que entrou para a história como a Primavera de Praga, tinha como fundamento um programa de reformas políticas que extinguia a censura e estimulava as pessoas a se encontrarem para discutir e sonhar com uma sociedade aberta, solidária, fraternal e democrática. Em suma, pretendia "construir um socialismo com face humana", o lema do movimento.

Apesar das manifestações contra a invasão da Checoslováquia e dos protestos no interior da própria União Soviética, o movimento em Praga, aos olhos da maioria dos partidos de Esquerda, estava na contramão da história, pois enfraquecia o socialismo. No entanto, outras vozes somaram-se às da Checoslováquia, como a do Partido Comunista Italiano. O secretário do PCI, Luigi Longo, responsabilizou a União Soviética pela invasão. Era a primeira condenação à URSS desde a fundação do PCI, em 1921. Com essa atitude, o partido mantinha-se fiel à sua doutrina do policentrismo, que defendia que cada país realizasse o socialismo da maneira que julgasse mais conveniente.

Por sua vez, a União Soviética justificava a invasão com o argumento de que a Checoslováquia tentava retornar ao capitalismo. Não obstante o protesto de alguns PCs e de grupos trotskistas, esses últimos caracterizando a rebelião de Praga como a emergência de uma revolução política contra o socialismo de Estado, a versão oficial da URSS tornou-se predominante na maioria das organizações de esquerda, inclusive na América Latina. 
No cenário internacional, a situação da América Latina agravava-se pela existência das ditaduras militares. $\mathrm{O}$ movimento estudantil, que, na maior parte das vezes, - se iniciou com reivindicações específicas no interior das universidades, incorporou a luta política contra os governos militares. No interior do movimento predominavam duas orientações distintas, mas não necessariamente opostas: a reivindicativa e a revolucionária. Essas eram as interfaces do movimento, segundo Foracchi (1972, p. 88):

É difícil precisar os limites dessa distinção, pois, na prática estudantil, elas com frequência se entrecruzavam dissolvendo-se uma na outra. O efeito revolucionário ou reivindicativo, da contestação estudantil, depende da repercussão que alcançam em termos do sistema social, e da capacidade que este mobiliza no sentido de imprimir-lhes uma canalização institucional ou reprimi-las, radicalizando-as.

Os jovens exprimiam o sentimento de indignação da sociedade com o regime político e pertenciam a uma geração disposta a dar a vida pela liberdade. ${ }^{2}$ Eis a característica principal do movimento estudantil daquele período. A rebelião dos jovens na América Latina logo ecoou como uma luta contra as ditaduras militares. O cenário de 1968 no Brasil, vértice dessa revolução da juventude, não foi diferente de outros países, como descreve Ventura (1988, p. 14):

$\mathrm{Na}$ verdade, a aventura dessa geração não é um folhetim de capae-espada, mas um romance sem ficção. $\mathrm{O}$ melhor do seu legado não está no gesto - muitas vezes desesperado; outras, autoritário - mas na paixão com que foi à luta, dando a impressão de que estava disposta a entregar a vida para não morrer de tédio. Poucas - certamente nenhuma depois dela - lutaram tão radicalmente por seu projeto, ou por sua utopia. Ela experimentou os limites de todos os horizontes: políticos, sexuais, comportamentais, existenciais, sonhando em aproximá-los sempre.

No Brasil, manifestações específicas contra o acordo MECUsaid e por mais vagas e mais verbas nas universidades públicas vincularam-se à luta contra o imperialismo norte-americano e 
a ditadura militar. Era a versão brasileira da palavra de ordem francesa: "Seja realista, exija o impossível." Já no mundo artístico, a bandeira apropriada era "a imaginação no poder". Imersos no clima de rebeldia, os jovens importaram também de Paris o slogan "É proibido proibir", que expressava o desejo de liberação em todos os sentidos. A política tinha primazia sobre as outras atividades, pois tudo era político. "O pessoal é político", era a compreensão da época.

Vivia-se uma revolução social e cultural, no mundo dos costumes e das artes. E a revolução cultural chegava a ser mais abrangente do que o movimento político porque rompia com um estilo de vida. A contracultura manifestava-se como radicalmente oposta às formas tradicionais de criação e, dificilmente, era assimilável à noção racional da política que norteava o movimento estudantil.

A contracultura ultrapassava o nível da ideologia e propunha, como meta, a transformação profunda do estilo de vida moderno, na medida em que esse era culturalmente modelado à imagem da sociedade. Para Foracchi (1972, p. 93), o percurso da "geração à revolução" é tortuoso, principalmente quando se leva em conta que o significado da "revolução" pode ser concretizado, tanto por meio da política com que o movimento estudantil está identificado, quanto no movimento da contracultura em geral, que congrega uma atitude de repúdio às formas de vida possíveis na sociedade moderna.

No Brasil, o ano que começou com passeatas por mais vagas e mais verbas nas universidades públicas terminou com a luta contra a ditadura militar e com a decretação do Ato Institucional $\mathrm{n}^{\circ} 5$, em 13 de dezembro, que fechou o Congresso Nacional e cassou direitos políticos. O movimento estudantil entrou em descenso. $\mathrm{O}$ chamado golpe dentro do golpe intensificou a repressão, iniciando o que foi denominado de "anos de chumbo". Porém, mesmo enfraquecido, ao ser colocado contra a parede o movimento reagiu com a palavra de ordem: A luta continua! 
Com a intensificação da repressão, boa parte dos grupos de esquerda que atuava no movimento estudantil aderiu à luta armada. O debate político, antes voltado para as manifestações de massa, transportou-se para o campo da guerra popular e da guerrilha. A experiência e os ensinamentos vinham, principalmente, da China, Vietnam e Cuba. Che Guevara, morto em 1967, tornou-se um ícone. Sua imagem, como aquele que unia coragem e ternura, transformou-o no tipo ideal do homem socialista. Das fileiras do movimento estudantil saíram os guerrilheiros nos anos 70 .

O movimento estudantil na década de 60 tinha um caráter emancipatório. Seu poder vinha de convicções comuns, da desobediência civil, da confrontação com o poder com base na livre união dos indivíduos contra os instrumentos coercitivos do aparelho estatal, mantido pela violência. Em nenhum outro tempo depois se agiu com tanto desprendimento e paixão, com tamanha ousadia.

Os rebeldes de 1968 se entregaram à luta pela liberdade a todo custo. Seus ideais eram próprios daquele tempo. Movidos pela coragem e pelos desafios da época, nem conseguiam perceber direito os paradoxos existentes de que, ao lutarem pela liberdade, defendiam também regimes autoritários. Após trinta anos, essa foi a crítica de Cohn-Bendit (1998), um dos líderes do Maio francês:

A grande diferença entre os jovens de 68 e os de hoje é que nós não tínhamos medo do futuro. O futuro era nosso e a nossa briga era para vivê-lo como a gente bem entendia. Contudo nós não tínhamos razão em tudo. Falávamos em liberdade, desfilando com o retrato de Mao Tsé-Tung; outros protestavam contra o autoritarismo, carregando o de Fidel ou de Ho Chi Min.

A década de 60 ficou como referência para a Esquerda do mundo todo que, durante anos, reproduziu aquela utopia. O legado da geração de 68 é o de ter assumido um destino coletivo de lutar por um mundo melhor. Nos anos posteriores, vieram as críticas, questionamentos das táticas políticas, mas a opção socialista 
permaneceu como a matriz da Esquerda. Em seu balanço, tinha valido a pena e ainda valia lutar pela revolução socialista.

Os anos 80 trouxeram novos desafios para o pensamento de Esquerda, com especificidades para o da América Latina e do Brasil. No país, o primeiro deles foi compreender o processo de redemocratização e os novos parâmetros das lutas sociais. Nos movimentos que caracterizam o final do regime militar e a transição política, há um deslocamento da palavra de ordem de "revolução" para "democracia" (Weffort, 1984).

Ao lado da defesa da democracia - antes considerada uma palavra de ordem democrático-burguesa-surge um novo vocabulário nas lutas sociais. No arcabouço da defesa da democracia outros conceitos são incorporados, como os de cidadania e sociedade civil, termos pouco referidos anteriormente. O conceito de democracia como valor universal é incorporado na linguagem da Esquerda (Coutinho, 1984). Entretanto, o socialismo como modelo de sociedade permanece como seu objetivo.

\section{3}

O modelo socialista entrou em crise quando, em 1989, o mundo foi surpreendido com a queda do Muro de Berlim e, em 1991, com o fim do socialismo no Leste Europeu. A esquerda mal tinha se reorientado na nova conjuntura política, refazendo bandeiras da década de 60 , como substituir o conceito de revolução por democracia, quando vivenciou o fim de uma utopia. Na época, já lidava com alguma teorização sobre a importância das bandeiras democráticas, mas o marxismo-leninismo ainda permanecia como forte representação no seu arquétipo político.

Com o fim do socialismo real, o debate em torno da democracia e da liberdade ganhou prioridade. Na teoria e na prática tornou-se 
insustentável a defesa do socialismo sem a garantia das liberdades democráticas. Com isso, propostas que antes integravam o programa da esquerda - como a ditadura do proletariado, ou distinções como partidos burgueses, partidos revolucionários de massa e partidos quadros - herdadas da ortodoxia marxista-leninista, perderam a pretensão de legitimidade.

Mesmo que já existissem críticas ao socialismo de Estado, foi com o colapso do socialismo real que a defesa desse modelo tornouse insustentável. Serge (1987), intelectual bolchevique dissidente, registrou em suas memórias as perseguições e mortes do partido, ainda sob o comando de Lenin. Michels (1972), com base na análise da estrutura e organização dos partidos operários de massa, descreve o processo de formação das oligarquias partidárias, fenômeno que denominou de "lei de ferro das oligarquias".

Arendt, como foi mencionado, criticou o totalitarismo soviético, mas não assistiu à sua queda. Em 1970, cinco anos antes de sua morte, em entrevista concedida ao escritor alemão Adelbert Reif, negou-se a fazer comparações entre o capitalismo e o socialismo como modelos opostos, situando no centro da discussão a questão dos direitos civis e da própria compreensão da política:

Liberdade é liberdade quer seja garantida pelas leis de um governo 'burguês' ou por um Estado 'comunista'. Do fato de que os governos comunistas não respeitam hoje os direitos civis e não asseguram liberdade de expressão e associação não decorre que tais direitos e liberdade sejam 'burgueses'. [...]

Eu repito: a questão é pura e simplesmente se eu posso falar e imprimir o que eu quiser, ou se não posso; se meus vizinhos me espionam ou não. Liberdade sempre implica liberdade de divergir. (Arendt, 1999, p. 190).

Após a queda do socialismo real, reacende-se um debate sobre a própria pertinência dos conceitos de esquerda e direita, na medida em que surgiram questionamentos sobre os fundamentos 
dessa distinção. Bobbio vai defender a validade do uso desses conceitos. Argumenta que o traço distintivo da Esquerda é o de ressaltar o princípio da igualdade, sem abrir mão, evidentemente, do princípio da liberdade. Segundo ele, é papel da Esquerda manifestar sua indignação com as iniquidades sociais:

Nenhuma pessoa de esquerda (sinistrorso) pode deixar de admitir que a esquerda de hoje não seja mais a de ontem. Mas, enquanto existirem homens cujo empenho político seja movido por um profundo sentimento de insatisfação e de sofrimento perante as iniquidades das sociedades contemporâneas - hoje talvez menos ofensivas do que em épocas passadas, mas bem visíveis -, eles carregarão consigo os ideais que há mais de um século têm distinguido todas as esquerdas da história. (Bobbio, 1995, p. 23-24).

Giddens assevera que há um esgotamento da Esquerda nos moldes tradicionais, todavia afirma que o neoliberalismo igualmente está em crise. Sugere como proposta alternativa aos dois modelos a política da terceira via:

A terceira via se refere a uma estrutura de pensamento e de prática política que visa a adaptar a social-democracia a um mundo que se transformou fundamentalmente ao longo das duas ou três últimas décadas. É uma terceira via no sentido de que é uma tentativa de transcender tanto a social-democracia do velho estilo quanto ao neoliberalismo. (Giddens, 1996, p. 36).

De acordo com o autor, a terceira via consiste em uma social-democracia revigorada. Suas principais características são: a democratização da democracia; a reflexividade social; o resgate do conceito de público para além do Estado. A reflexividade social baseia-se em uma dimensão dialética que reúne interação social e cidadania ativa. A proposta da terceira via visa à responsabilidade pessoal, à reconstrução das instituições públicas e ao fortalecimento da sociedade civil. 


\section{4}

No século 21, após tantos reveses na história da esquerda, não é mais possível pensá-la nos marcos do passado, da desapropriação da propriedade privada e da ditadura do proletariado. Por sua vez, a esquerda de 1968 que, com sua utopia, transformou a visão tradicional do mundo, se nutriu muito desse modelo. A esquerda depois da queda do Muro de Berlim sofreu grande golpe. Qual sua identidade no momento?

Uma nova esquerda se caracteriza pelo resgate definitivo do conceito de liberdade e pela rejeição a qualquer forma de autoritarismo. Seu perfil se define pela identidade com o interesse público. A geração de 1968 demonstrou a importância da participação na vida pública e como a dimensão da política pode modificar as pessoas. Ao participar da vida pública, aquela geração descobriu a 'felicidade pública' que significa abrir para si uma dimensão de experiência humana que, de outra forma, não desenvolveria.

A política, no sentido da ação compartilhada na vida pública, possibilita que os indivíduos atinjam sua plena realidade como homens, na medida em que não apenas existem para eles mesmos, mas aparecem para os outros. Essa é a origem da postura ética: aparecer para si mesmo como gostaria de aparecer quando visto pelos outros.

De acordo com autores citados, pode-se dizer que a única Esquerda que hoje pode falar alguma coisa para o futuro tem de ser democrática, que define o sentido da política como coisa pública, que se compromete com a defesa da cidadania, e que luta pela justiça social. Em suma, que não abdica da defesa da liberdade como valor fundamental e razão de ser da política. 


\title{
Notas
}

1 A análise sobre a geração de 1968 é reproduzida de Coelho (2006).

2 Sobre o conceito de gerações, ver Mannheim (1983, 1993).

The Left of yesterday and of today: the dilemma between equality and freedom

\begin{abstract}
This article deals with the ideas of the Left in the 1960's and the changes in leftist ideas and politics in the 1990's, after the collapse of the Berlin Wall and the demise of socialism. It focuses on a conflict that has been present in the history of socialism: the question o civil rights. The article also analyzes the dilemmas of the Left of yesterday and of today, with an emphasis on the relationship between politics and freedom. It suggests that concomitant with the defense of social justice, the identity of the contemporary Left is largely defined by the defense of freedom as a fundamental value and the very essence of politics.
\end{abstract}

Keywords: Left models; socialism; political freedom; authoritarianism: democracy.

\section{Referência bibliográficas}

ARENDT, Hannah. A condição humana. Rio de Janeiro: ForenseUniversitária, 1987.

. O que é Liberdade? In: . Entre o passado e futuro. São

Paulo: Perspectiva, 1972.

. Origens do totalitarismo. São Paulo: Companhia das Letras, 1989.

. Reflexões sobre política e revolução. In: . Crises da República. São Paulo: Perspectiva, 1999. 
BAUMAN, Zygmunt. Comunidade: a busca por segurança no mundo atual. Rio de Janeiro: Jorge Zahar, 2003.

BELIN, Isaiah. Quatro ensaios sobre a liberdade. Brasília: Ed. Universidade de Brasília, 1981.

BOBBIO, Norberto. Direita e esquerda: razões e significados de uma distinção política. São Paulo: Ed. Universidade Estadual Paulista, 1995.

BRANDÃO, Gildo Marçal. A esquerda positiva: as duas almas do Partido Comunista. São Paulo: Hucitec, 1997.

COELHO, Maria Francisca Pinheiro. Os dois marxismos de Marx. In: FREITAG, Barbara; COELHO, Maria Francisca Pinheiro (Orgs). Marx morreu: viva Marx! Campinas, SP: Papirus, 1993.

. Movimento estudantil marca a era dos extremos. Democracia viva, Rio de Janeiro, n. 30, p. 94-98, jan./mar. 2006.

COHN-BENDIT, Daniel. Isto É, p. 138, 3 jun. 1998.

COUTINHO, Carlos Nelson. A democracia como valor universal e outros ensaios. 2 ed. Rio de Janeiro: Salamandra, 1984.

FORACCHI, Marialice Mencarini. A juventude na sociedade moderna. São Paulo: Pioneira, 1972.

GIDDENS, Anthony. A terceira via e seus críticos. Rio de Janeiro: Record, 2001.

- Para além da esquerda e da direita: o futuro da política radical. São Paulo: Ed. Unesp, 1996.

HABERMAS, Jürgen. A inclusão do outro: estudos de teoria política. São Paulo: Loiola, 2002.

HOBSBAWM, Eric. Era dos extremos: o breve século XX: 1914-1991. São Paulo: Companhia das Letras, 1995.

LUXEMBURGO, Rosa. A revolução russa. In: GUIMARÃES, Juarez R. (Org.). Rosa, a vermelha. São Paulo: Busca Vida, 1987. 
MANNHEIM, Karl. El problema de las generaciones. Revista Española de Investigaciones Sociológicas, n. 62, abr./jun. 1993.

. Funções das gerações novas. In: PEREIRA, Luiz; FORACCHI, Marialice M. Educação e sociedade: leituras de sociologia da educação. 11. ed. São Paulo: Companhia Editora Nacional, 1983.

MICHELS, Robert. Sociologia dos partidos políticos. Brasília: Ed. Universidade de Brasília, 1972.

SERGE, Vitor. Memórias de um revolucionário. São Paulo: Companhia da Letras, 1987.

TOCQUEVILLE, Alexis. A democracia na América. 2. ed. Belo Horizonte: Itatiaia; São Paulo: Ed. Universidade de São Paulo, 1977. . O antigo regime e a revolução. Brasília: Ed. Universidade de Brasília, 1979.

VENTURA, Zuenir. 1968: O ano que não terminou. Rio de Janeiro: Nova Fronteira, 1988.

WEFFORT, Francisco. Por que democracia? São Paulo: Brasiliense, 1984. 